DOE Report No. DOE/ER/45163-46

Technical Progress Report

FINAL

Title and Subtitle:

Principal Investigator:

Reporting Period:

Date Submitted:

DOE Sponsorship and Grant No.:

\section{X-RAY and T-RAY SPECTROSCOPY of SOLIDS UNDER PRESSURE}

Robert L. Ingalls, Professor

Department of Physcis, Box 351560

University of Washington

Seattle, Washington 98195

November 1993 - October 1996

April 30, 1996

Prepared for the U.S. Department of Energy under Grant No. DE-FG06-84ER45163

This report was prepared as an account of work sponsored by the United States Government. Neither the United States nor the United States Department of Energy, nor any of their employees, makes any warranty, express or implied, or assumes any legal liability or responsibility for the accuracy, completeness, or usefulness of any information, apparatus, product, or process disclosed, or represents that its use would not infringe privately owned rights. Reference herein to any specific commercial product, process or service by trade name, mark, manufacturer, or otherwise, does not necessarily constitute or imply its endorsement, recommendation, or favoring by the United States Government or any agency thereof. The views and opinions of authors expressed herein do not necessarily state or reflect those of the United States Government or any agency thereof.
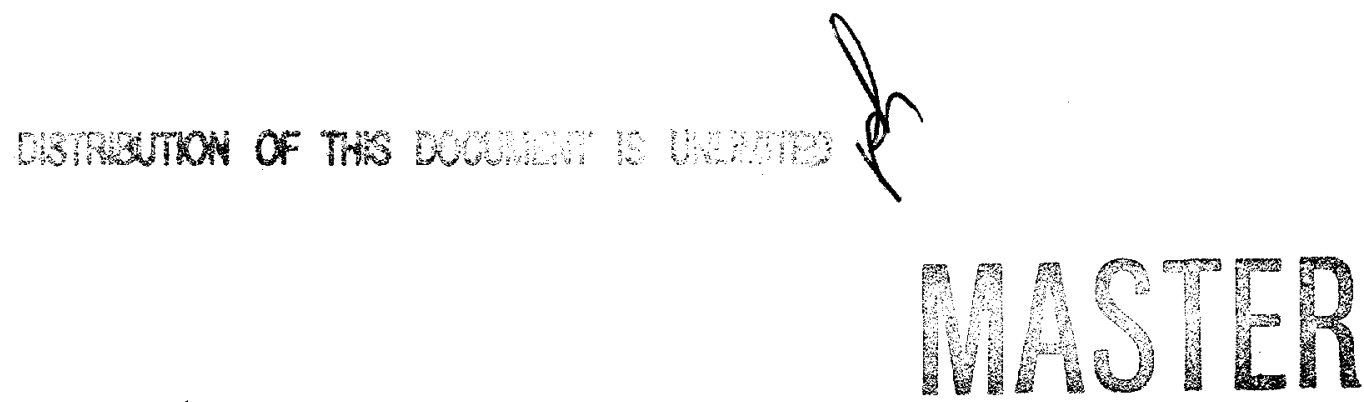


\section{DISCLAIMER}

This report was prepared as an account of work sponsored by an agency of the United States Government. Neither the United States Government nor any agency thereof, nor any of their employees, make any warranty, express or implied, or assumes any legal liability or responsibility for the accuracy, completeness, or usefulness of any information, apparatus, product, or process disclosed, or represents that its use would not infringe privately owned rights. Reference herein to any specific commercial product, process, or service by trade name, trademark, manufacturer, or otherwise does not necessarily constitute or imply its endorsement, recommendation, or favoring by the United States Government or any agency thereof. The views and opinions of authors expressed herein do not necessarily state or reflect those of the United States Government or any agency thereof. 


\section{DISCLAIMER}

Portions of this document may be illegible in electronic image products. Images are produced from the best available original document. 
Summary of Progress

\section{X-Ray and T-Ray Spectroscopy of Solids under Pressure}

\section{Introduction}

This report briefly describes our studies of various materials at high pressures, in the last three years, by means of $\mathrm{x}$-ray and $\gamma$-ray absorption spectroscopy. High pressure provides a very effective means of studying materials. Virtually every property is altered, from the color and crystal structure, to the electrical and magnetic properties. The fundamental reason, of course, is that the quantum levels depend upon the atomic spacing, so that both the electronic and vibrational structure are affected.

Synchrotron $\mathrm{x}$-ray absorption spectroscopy, which probes materials on the microscopic level is quite well suited to high pressure studies. Moreover, since this field is still being developed, the ability to alter the microstructure of a material by means of high pressure aids in our understanding of the theory underlying the x-ray absorption spectra. Here we shall frequently refer to XAFS ( $\mathrm{x}$-ray absorption fine structure) which covers both XANES (x-ray absorption near- edge structure) as well as EXAFS (extended x-ray absorption fine structure). As the studies here show, this technique is especially sensitive to valence states, electronic structure, atomic vibrations, bond lengths, coordination numbers and atomic rearangement during phase transitions. During this report period we have been able to obtain high qualilty synchrotron beam time from the Stanford Synchrotron Radiation Laboratory and the National Synchrotron Light Source, at a rate of approximately one week per year.

Gamma-ray absorption spectroscopy, the Mössbauer Effect, which is somewhat complimentary to XAFS, is also well-suited to high pressure science. It probes the effect of the solid state environment on a nuclear transition taking place in an atom or ion within that solid. This method then probes internal magnetic and electric fields, internal electron density at the nucleus as well as atomic vibrations. These quantities are sensitive to the valence state and local atomic surroundings, and to changes, such as phase transitions. 


\section{Pressure Induced Crystalline Transitions}

The pressure-induced $\mathrm{B} 1-\mathrm{B} 2$ transition ( $\mathrm{NaCl}$ to $\mathrm{CsCl}$ structure) has been extensively studied at room temperature (RT) in a number of the alkali metal halides, in particular $\mathrm{RbCl}$ for which the transformation occurs at approximately $0.5 \mathrm{GPa}$. Of particular interest is the large volume decrease of approximately $14 \%$, and a possible relationship between the crystal axes in the two phases. Using a new cryostat, described in section VIII. we have conducted liquid nitrogen temperature (LNT) Rb K-edge XAFS measurements of this transition as well as a state-of-the-art analysis of both the LNT and the previous RT data using the FEFF curved-wave, multiple scattering program. We find from the XANES spectra at LNT that the B1-B2 phase transition is much more gradual compared to the sharper RT transition. In Fig. 1 are shown the associated XAFS oscillations versus wave number. The change in character due to the phase transition is more apparent in such a plot. Also shown for comparison is the RT result at atmospheric pressure. High pressure

and, especially, low temperature enhances the amplitude of these oscillations by reducing the mean-square deviations in the bond-lengths. The radial distribution about the $\mathrm{x}$-ray absorbing atom is readily obtained from the magnitude of the Fourier transform of the type of data of Fig. 1. and is shown for the LNT data in Fig. 2, where the gradual change in structure due to the phase transition is evident.

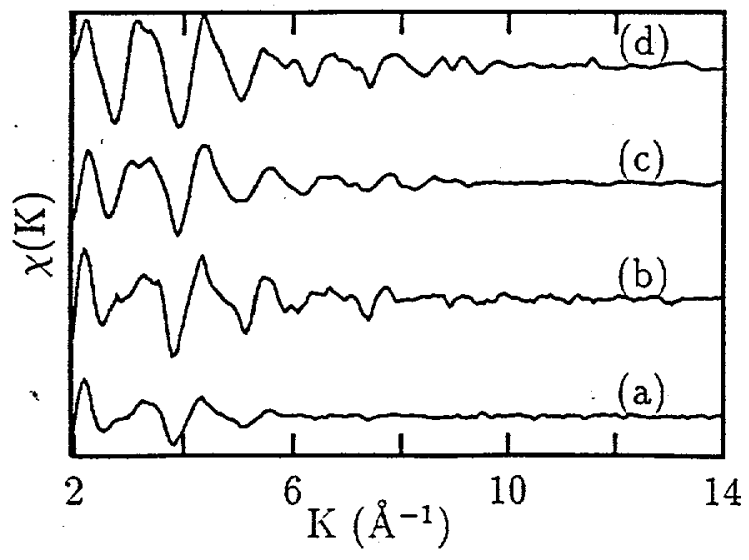

Fig. 1. EXAFS oscillationa at the $\mathrm{Rb} \mathrm{K}$-edge in $\mathrm{RbCl}$ at several temperatures and pressures: (a) RT and $0.1 \mathrm{MPa}$; (b) - (d) LNT and 0.1 MPa, 0.3 and $0.7 \mathrm{GPa}$, respectively.

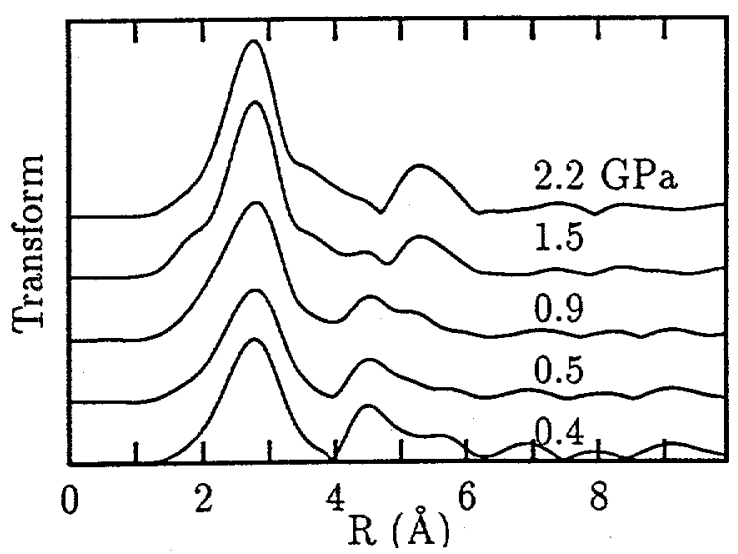

Fig. 2. EXAFS determined radial distribution functions about the $\mathrm{Rb}$ ions in $\mathrm{RbCl}$ at $\mathrm{LNT}$ and several pressures. 
Good fits to the data were obtained assuming both $\mathrm{B} 1$ and $\mathrm{B} 2$ phases to be present in this region at the same pressure. The relative amounts of the two phases are shown in Fig. 3. for both RT and LNT. If instead, sizeable pressure gradients are used to explain the presence of both phases, one would expect to extract different pressures for each phase, with the B1 phase yielding the lower pressure. This is not observed. In fact, it is common for Martensitic phase transitions to exhibit mixed phase regions that decrease in pressure range as the temperature is raised. Very recently we have begun a similar study of the 1.7 $\mathrm{GPa}$ transition in $\mathrm{KBr}$. Our initial analysis indicates there is a broader mixed phase region in this case even at room temperature. Of course these systems show a pronounced hysteresis as pressure is reduced.

The bcc-hcp transition in metallic iron is another such example of a Martensitic transition that shows a broad mixed phase region in the pressure region 13 to over $21 \mathrm{GPa}$ at room temperature as well as hysteresis. Our previous report discussed our results for this region. For example our XAFS radial distribution showed a rich evolvement of the one structure to the next, much like Fig. 2 does for $\mathrm{RbCl}$. In a careful FEFF multiple scattering analysis, we found the structure of pure phases to be in excellent agreement with the latest $x$-ray diffraction results. For the bcc phase, our fit to the data involved 25 paths with 8 variables and 42 paths with 10 variables for the hcp phase. The variables include lattice constants and mean-square-relative-displacements, $\sigma^{2}$ for several coordination shells. We show in Fig. 4 the fitted first shell results of the latter, versus relative volume, into the transition.

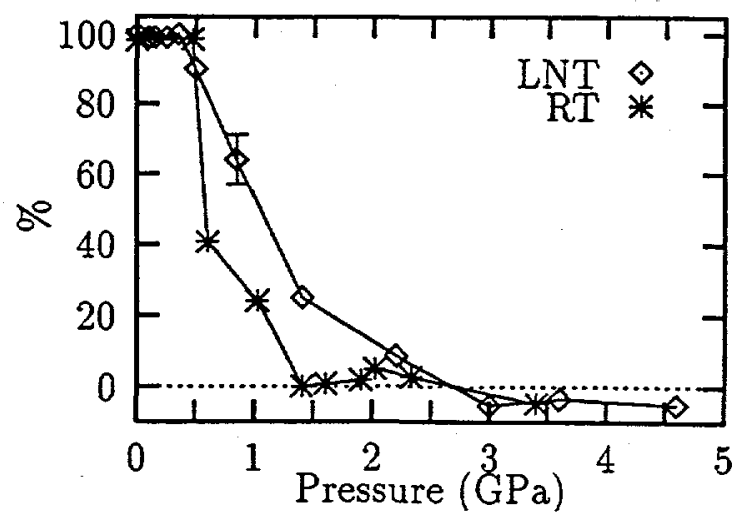

Fig. 3. Percentage of the $\mathrm{B} 1$ phase of $\mathrm{RbCl}$ at $\mathrm{RT}$ and LNT as functions of pressure.

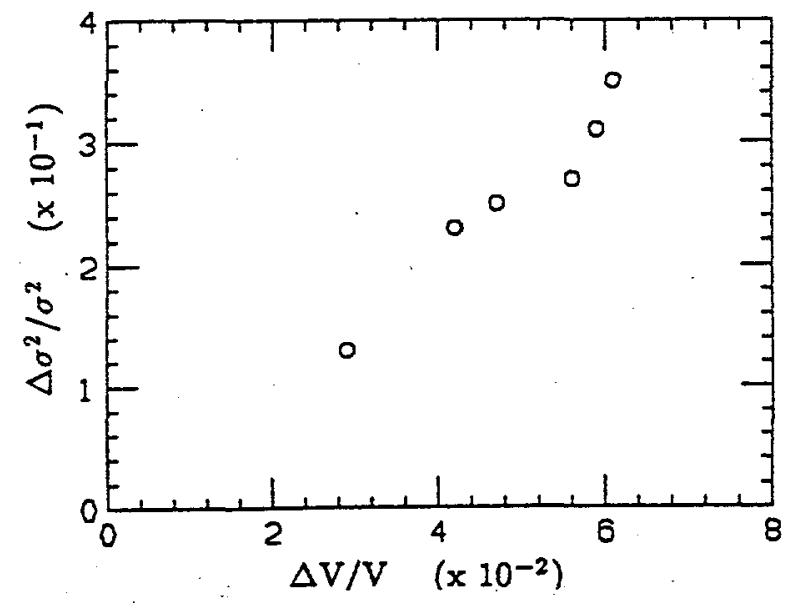

Fig. 4. $\sigma^{2}$ versus volume for metallic iron. 
Another recent study was the pressure induced Wurtzite to $\mathrm{B} 1$ transition in $\mathrm{ZnO}$ which occurs at approximately $10.5 \mathrm{GPa}$. Fig. 5 shows the change in the Zn K-edge XAFS as one proceeds through the transition. We find the transition to be relatively sharp at RT. (The measurement at LT has yet to be performed.) We are also currently analyzing extensive data on metallic zinc. Although no transition with pressure occurs, nor was expected, this will be an important test case for the FEFF analysis package. The reason is that anharmonic contributions are very important, so that ignoring them would lead one to conclude that the material contracts upon heating !

Fig. 5. EXAFS of the $\mathrm{Zn} \mathrm{K}$-edge in $\mathrm{ZnO}$ through the 10.5 GPa Wurtzite to B1 structural phase transition: curves $a$ to $d$ are in order of increasing pressure, with $a$ and $b$ below the transition and $\mathrm{c}$ and $\mathrm{d}$, above.

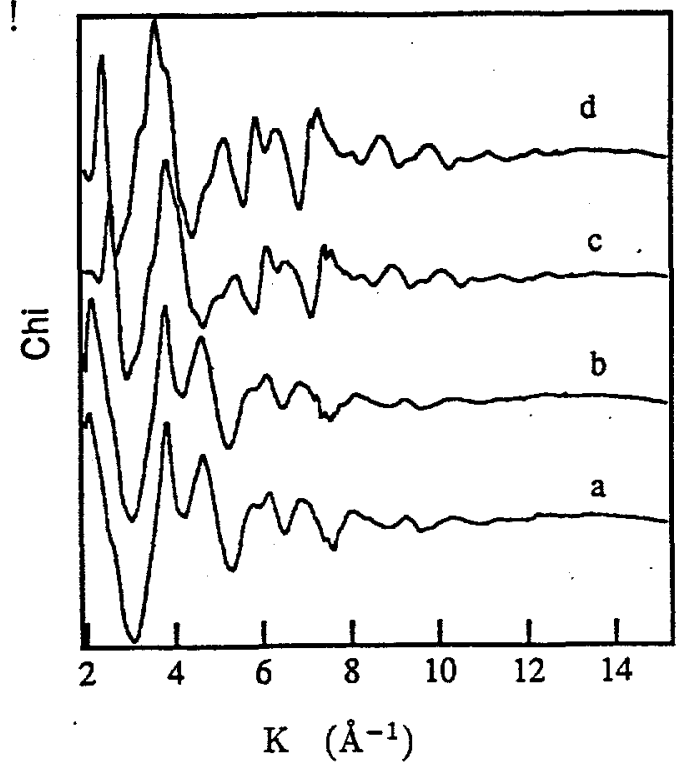

\section{Pressure Induced Amorphization}

Most amorphous materials have been prepared by rapid cooling of the liquid phase. Recent work has also shown that the amorphous state can also be obtained by hydrostatic pressurization of certain crystals. Pressure induced amorphous states, like conventionally prepared amorphous materials, have broad halo like x-ray diffraction paterns. In some cases the crystalline state is recovered upon decompression. The molecular crystal, tin. tetraiodide $\left(\mathrm{SnI}_{4}\right)$, is a particularly interesting example. Diffraction studies show it to transform to a metallic amorphous state between 9 and 18 GPA and transform again to a similar crystalline phase ca $40 \mathrm{GPa}$. The same transformations in reverse also take place. How the the translational structural information hides in apparently disorderd configurations is a very interesting question. Study of the local structure of this new kind of disorder is essential in understanding the mechanism of pressure induced amorphization. 
We have made an XAFS study of both the $\mathrm{Sn}$ and I K-edges in $\mathrm{SnI}_{4}$ to pressures in excess of $22 \mathrm{GPa}$. In the low pressure phase the $\mathrm{SnI}_{4}$ molecules have tetrahedral symmetry, forming a cubic lattice. Sn K-edge spectra at different pressures are shown in Fig. 6. We observe that the amplitude of the oscillations in the high $\mathrm{k}$ range $\left(8 \AA^{-1}-16 \AA^{-1}\right)$ drops considerably above $9 \mathrm{GPa}$, and then gradually decreases until it totally disappears at $19 \mathrm{GPa}$, only returning to its orignal value after release of pressue. We interpret this as a distortion of the $\mathrm{SnI}_{4}$ molecule due to pressurization, and then a restoration after pressure release. Because the iodine atoms in crystalline $\mathrm{SnI}_{4}$ interact very weakly with their iodine neighbors, the amplitude of the associated spectra is very small. However, at high pressure, the iodine atoms form stronger bonds among themselves and the amplitude of the XAFS spectra increases (see Fig. 7).

Our results from a detailed analysis of the distances obtained from fitting the data of the Sn-I bond indicate the $\mathrm{SnI}_{4}$ tetrahedra hardly compress in the crystalline phase but are somewhat expanded and disordered in the amorphous phase that coexists above about $9 \mathrm{GPa}$. At the same time an I-I bond decrease in size and strengthens. We have made computer simulations that agree with these results. What seems to happen is that pairs of tetrahedra along the [111] type axes undergo correlated rotations and translations and possibly form dimers in the amorphous state. Very recently we have made additional measurements to further examine what is happening.
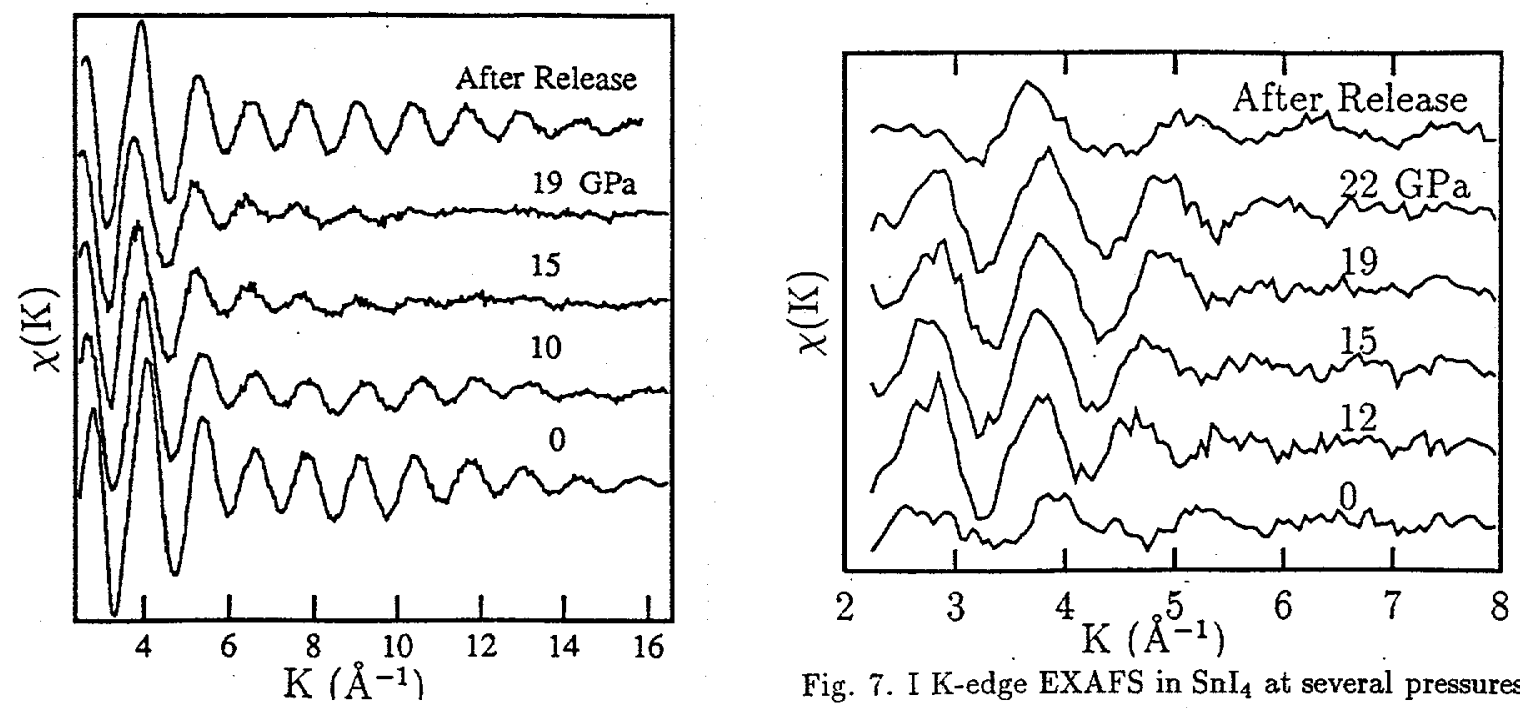

Fig. 7. I K-edge EXAFS in $\mathrm{SnI}_{4}$ at several pressures.

Fig. 6. Sn K-edge EXAFS in $\mathrm{SnI}_{4}$ at several pressures. 


\section{Pressure Induced Octahedral Rotations}

Improvements in the quality of XAFS data and analysis, such as the FEFF package of our colleague, J. J. Rehr, have permitted measuring the behavior around the absorbing atom out to the fourth coordination shell. These measurements then enable the determination of bond angles. One reason is that when there are atoms in between that which is photoexcited and that which is contributing to the backscattering, causing the XAFS oscillations, there are multiple-scattering pathways which enhance the effect. Another reason is more precise determinations of the scattering path lengths themselves.

We are applying these ideas to several systems. For instance in the perovskite material, $\mathrm{ReO}_{3}$, pressure causes a second-order transition, at $0.5 \mathrm{GPa}$, in which the $\mathrm{ReO}_{6}$ octahedra undergo a rotation along [111] type axes preserving the cubic symmetry. We have taken $\operatorname{Re} \mathrm{L}_{3}$-edge spectra in this system. Figs. 8 and 9 indicate the quality of the results. Our analysis of such data indicates that above the transition the rotation angles gradually increase and are quite consistent with diffraction results. However below the transition there appears to be rotational disorder that, at this point, can either be static or dynamic. Recently we have taken more measurements on this system at both room temperature and liquid nitrogen temperature to elucidate this point. This study is continuing.

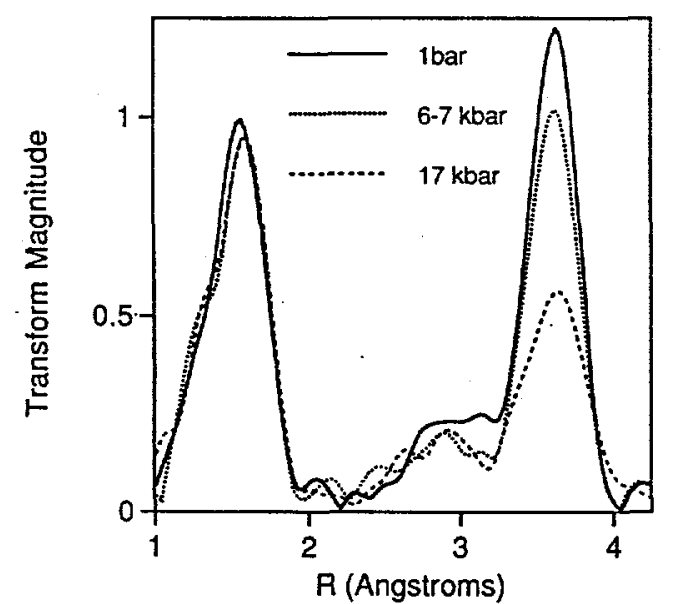

Fig. 8. XAFS of Re K-edge in $\mathrm{ReO}_{3}$ : Fourier-transformed $k^{2} \chi(k)$ spectra for three pressures. The window function for the transforms was a gaussian, symmetrically placed between 2 and $19 \AA^{-1}$.

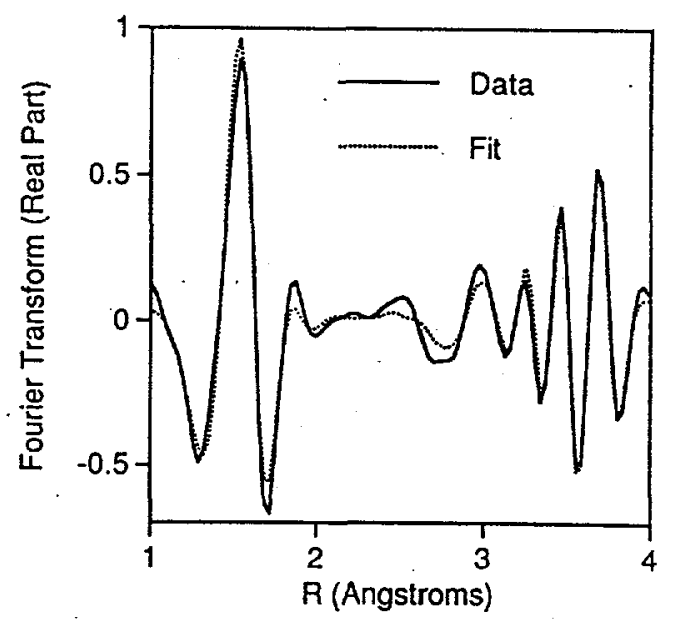

Fig. 9. XAFS of Re K-edge in $\mathrm{ReO}_{3}$ : Fit of the real part of the Fourier-transformed $k^{2} \chi(k)$ for a sample pressure of $1.7 \pm 0.3 \mathrm{GPa}$. 
In a related study we have measured the XAFS of the $\mathrm{Rb} \mathrm{K}$-edge and $\mathrm{W} \mathrm{L}_{3}$-edge in $\mathrm{Rb}_{.31} \mathrm{WO}_{3}$. The low pressure phase of this material, rubidium tungsten bronze, has a simple hexagonal structure, composed of layers of corner-linked $\mathrm{WO}_{6}$ octahedra, arranged in hexagonal rings. Each is common to two rings with each ring containing one $\mathrm{Rb}$ atom. Our work shows evidence of a pressure-induced structural phase transition in the vicinity of $2 \mathrm{GPa}$, which may be similar to the "compressibility collapse" transition in $\mathrm{ReO}_{3}$, discussed above. Our proposed high-pressure phase remains hexagonal, with the c-axis spanning two layers, rather that the one in the low pressure phase, with octahedra in successive layers tilting in opposite directions.

\section{Multiple Scattering Analysis of XANES}

The investigation of the electronic energy bands and local crystal structures of the ionic compounds is presently of great interest. In the last few years the XANES spectra have also shed light on the behavior in the neighborhood of phase transitions. Theoretical $\mathrm{K}$ edge XANES have been calculated using a band structure full multiple scattering approach for the $\mathrm{B} 1$ phases of $\mathrm{NaBr}$ and $\mathrm{AgBr}$ as well for $\mathrm{B} 1$ and $\mathrm{B} 2$ phases of $\mathrm{RbCl}, \mathrm{RbBr}$ and $\mathrm{KBr}$. For these latter structures and in spite of the close lattice parameters for both phases, the role of local symmetry around the absorbing site in the formation of the conduction band and resultings XANES of compounds investigated was able to be determined. The optimal cluster size that permited making a correct description of whole crystal in the B1 phase (the second shell of surrounding atoms for $\mathrm{AgBr}$ and more than 30 atoms for $\mathrm{RbCl}, \mathrm{KBr}$ ) was estimated. It was found that a single scattering approximation works well in $\mathrm{AgBr}$ and less satisfactory in $\mathrm{RbCl}, \mathrm{NaBr}, \mathrm{KBr}$, where multiple-scattering take place. The partial densities of $\mathrm{Br}$ and $\mathrm{Rb}$ p states in the conduction band of $\mathrm{RbBr}$ were obtained over a large energy interval for both the ground and the excited states. It was also found that the core hole potential weakly affected the conduction band electrons, therefore, one can derive the

projected p-density of state directly from experimental XANES data. This method shows how the electronic structure changes in selected phase transitions. Figs. 10 and 11 show 
the comparison between theory and experiment for the $\mathrm{Br} \mathrm{K}$-edge in $\mathrm{RbBr}$. It should be remarked that such an approach is satisfactory but will presumably ultimately improve when FEFF type analyses are extended further into the XANES region.

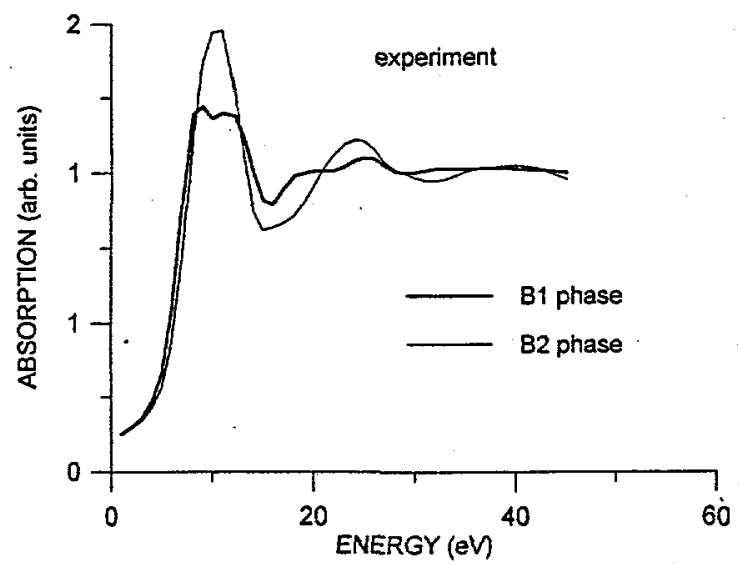

Fig. 10. XANES of the Br K-edge in RbBr: experimental.

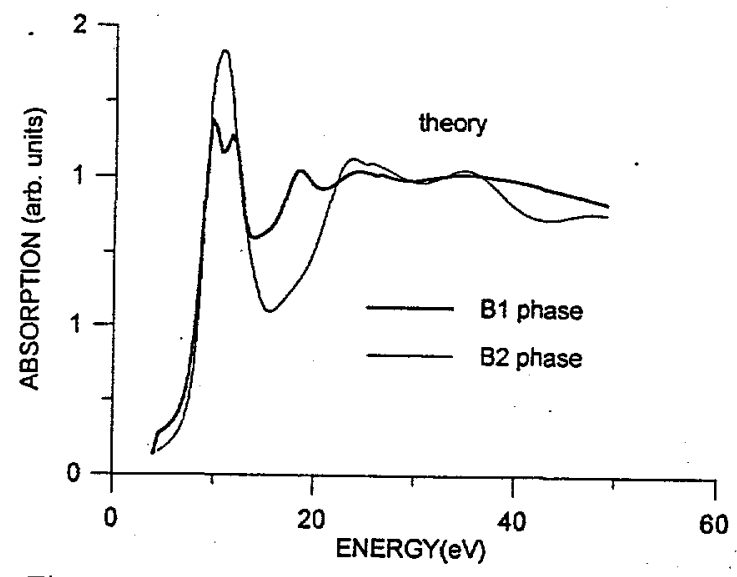

Fig. 11. XANES of the Br K-edge in RbBr: theoretical.

\section{Pressure Induced Structural Changes - New Initiatives}

Very recently we have initiated a series of investigations that brings together all of the issues raised in the previous sections. Since this new work constitutes the major part of the renewal proposal that accompanies this progress report, only a brief description is given here.

Measurement of the $\mathrm{Ag} \mathrm{K}$-edge spectra have been taken for $\mathrm{AgCl}$. This material and $\mathrm{AgBr}$ have been reported to undergo a transition from the $\mathrm{B} 1$ phase, at around $7 \mathrm{GPa}$, to another structure that remains to be conclusively determined. Our measurements indeed show evidence of such a transition which has also been predicted theoretically by A. Voronel and co-workers. Of even greater interest, however, according to the calculations, is that alloys of the above pure materials may undergo a type of bond buckling transition to an amorphous phase under pressure. Moreover there is reason to expect similar behaviors in alloys of of the alkali metal halides discussed in Section II. Both alloy systems have been shown by Voronel and co-workers to have a buckled structure at atmospheric pressure that does not show up in diffraction studies.

We have also undertaken new measurements in other oxide based perovskites. One 
such material is ferroelectric $\mathrm{KNbO}_{3}$. Our preliminary measurements of the $\mathrm{Nb} \mathrm{K}$-edge spectra show a transition above $12 \mathrm{GPa}$, possibly accompanied by octahedral rotations and reduced off-center displacements of the $\mathrm{Nb}$ atoms, presumably this high pressure phase is paraelectric. This appears to be consistent with what we recently found in the related system, $\mathrm{KTa}_{1-x} \mathrm{Nb}_{x} \mathrm{O}_{3}$. We also find increasing octahedral rotation in the related antiferrodistortive (AFD) system $\mathrm{K}_{1-x} \mathrm{Ta}_{x} \mathrm{O}_{3}$. Since some of the high $\mathrm{T}_{c}$ materials are also AFD, it is proposed that such a behavior is relevant to such superconductivity. Again, as found by Y. Yacoby and co-workers. oxide perovskites are also examples where XAFS indicates more static angular bond disorder that diffraction measurements.

\section{XAFS Experimental Advances}

This report period marks the achievement of a number of improvements in our XAFS spectroscopy at high pressures. These are due in part to the improved high intensity and stability of the synchrotron radiation from SSRL. Because of the greater flux we have been able to work with smaller beams, ca $200 \mu \mathrm{m}$ and therefore smaller samples. This in turn has permitted smaller high pressure anvil tips and the attainment of routinely higher pressures, ca $30 \mathrm{GPa}$, with boron carbide anvils. These advances have also permitted our going to higher energy x-ray absorption edges, such as our being able to study niobates and silver halides, and especially materials like $\mathrm{SnI}_{4}$ with $\mathrm{K}$-edges of 29 and $33 \mathrm{keV}$, respectively. Instead of using pressure calibrants of $\mathrm{Cu}, \mathrm{Br}$ or $\mathrm{Rb}$ we are beginning to utilize $\mathrm{Nb}$ or $\mathrm{Ag}$. We have also extended our work to lower temperatures with the development of a pressure cell that utilizes a diaphram pressurized by helium gas rather than the hydraulic oil used at room temperature. Of course advances in the analysis package, FEFF by our collegue, J. Rehr have aided the precision of our structure determinations. We are looking forward

to further advances provided by the anticipated move to the Advanced Photon Source, as discussed in the accompanying renewal proposal. 


\section{Mössbauer Studies}

We have studied the pressure dependence of $\mathrm{Na}_{2} \mathrm{Fe}(\mathrm{CN})_{5} \mathrm{NO} \cdot 2 \mathrm{H}_{2} \mathrm{O}$ (sodium nitropruside dihydrate), to $27 \mathrm{GPa}$ at room temperature using a diamond anvil cell and transmission Mössbauer spectroscopy. We have found two pressure induced partial phase transitions initiated around 21 and $27 \mathrm{GPa}$. We have also observed a sudden color change at $13 \mathrm{GPa}$, which is triggered by the blue He-Cd laser used for pressure calibration. However this optical change does not accompany any significant changes in the Mössbauer spectra. Ths first new phase occuring at $21 \mathrm{GPa}$ has considerably smaller quadrupole splitting and more positive isomer shift that the normal phase, closely resembling the oxidation reduced nitrosyl complex in water. On the other hand, the second new phase occurring at $27 \mathrm{GPa}$ shows a large quadrupole splitting and isomer shift characteristic of the $\mathrm{Fe}(\mathrm{II})$ high spin state. These new phases persist upon release of pressure over the time scale of 10 days. The explanation for these transitions is presumably the mechanism of charge transfer between the central iron atom and surrounding ligands.

In response to recent $\mathrm{x}$-ray diffraction measurements on iron at high pressures we have also initiated a Mössbauer investigation of this system, which is of geophysical interest. Iron shows a triple point around $10 \mathrm{GPa}$ and $800 \mathrm{~K}$ where the standard bcc phase meets the high termerature fcc and high pressure hcp phase. The reports by Saxena, et. al. and also Yoo, et. al. indicate that in the 1000-1400 K temperature region and 10-40 GPa vicinity of the fcc-hcp boundary, there may be new phases present. We have recently begun taking measurements on this system and have made this the main Mössbauer experiment to be conducted in our renewal proposal.

Fig. 12. Mössbauer transmission spectra of $\mathrm{Fe}^{57}$ in sodium nitroprusside during one pressure cycle (from bottom to top). The spectra marked with "*» were obtained during pressure release.

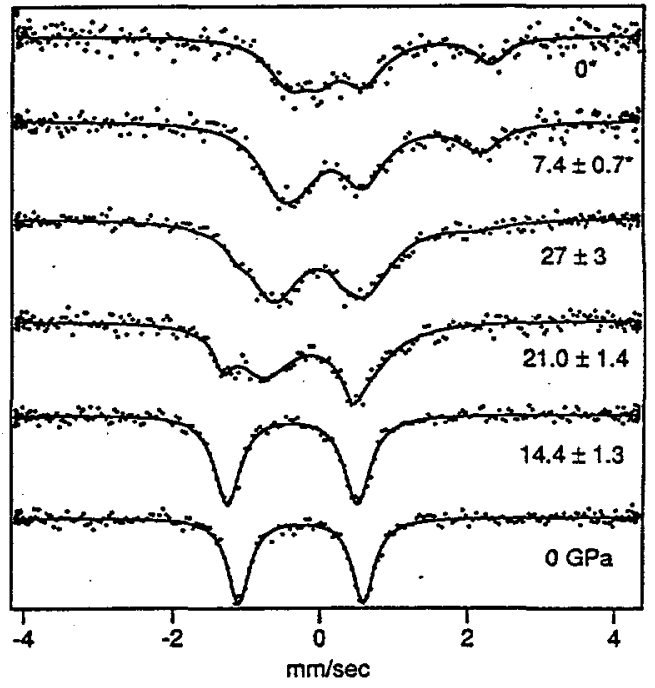




\section{Publications}

"Study of the Near Edge Background Determination in the Alkali Halides," P. Livins, R. Ingalls and J.J. Rehr, Jpn. J. Appl. Phys. 32, Suppl. 32-2, 116 (1993).

"XAFS Study of the bcc-hep Transition of Iron," F. Wang and R. Ingalls, Jpn. J. Appl. Phys. 32, Suppl. 32-2, 749 (1993).

"The Valence of Samarium in the Mixed-Valence Transition in SmSe," K.R. Bauchspiess, R. Ingalls and E.D. Crozier, Jpn. J. Appl. Phys. 32, Suppl. 32-2, 752 (1993).

"Pressure-Induced Transition in $\mathrm{Rb}_{31} \mathrm{WO}_{3}$ as Measured by XAFS," B. Houser and R. Ingalls, in High Pressure Science and Technology-1993, S. C. Schmidt, J.W. Shaner, G. A. Samara and M. Ross, Eds., ( American Institute of Physics, NY, 1994) p. 391.

"X-Ray Absorption Fine Structure Investigation of the High Pressure Phase of $\mathrm{KBr}$ and RbCl: Full Multiple-Scattering Analysis," A. V. Soldatov, T.S. Ivanchenko, I.E. Stekhin, A. Bianconi and R. Ingalls, Phys. Stat. Sol. B 84, 237, (1994).

"EXAFS Study of Pressure Induced Amorphization," F. Wang and R. Ingalls, Bull. Am. Phys. Soc. 40, 853 (1995).

"Local Symmetry Influence on the Formation of X-Ray Absorption Near Edge Structure in $\mathrm{KBr}$ and $\mathrm{RbCl}$," I.E. Stekhin, A. V. Soldatov and R. Ingalls, Physica B 208\&209, 286 (1995).

"Structural Parameters of $\mathrm{ReO}_{3}$ under Pressure from XAFS," B. Houser, R. Ingalls and J.J Rehr, Physica B 208\&209, 323 (1995).

"XAFS Study of Pressure Induced Amorphization," F. Wang and R. Ingalls, in High Pressure Science and Technology, W. Trzeciakowski, Ed. (World Scientific, Singapore, 1996) (in press).

"XAFS STudy of the B1-B2 Transition in RbCl." R. Ingalls, S. Jones and F. Wang, in High Pressure Science and Technology, W. Trzeciakowski, Ed. (World Scientific, Singapore, 1966)(in press).

"Electronic Structure of RbBr under Phase Transition: X-ray Absorption Near Edge Structure Analysis," A. V. Soldatov, I.E. Stekhin and R. Ingalls, J. Phys. C. (in press). 


\section{Reports and Presentations}

"Sodium Nitroprusside under High Pressure - Mössbauer Study," I. Choe and R. Ingalls, International Conference on the Applications of the Mössbauer Effect, Vancouver, B.C. Aug. 8-13, 1993.

"Structural Parameters of $\mathrm{ReO}_{3}$ under Pressure from XAFS," B. Houser, R. Ingalls and J.J. Rehr, 8th International Conference on X-Ray Absorption Fine Structure, Berlin, Aug. 28 - Sept. 2, 1994.

"Local Symmetry Influence on the Formation of X-Ray Absorption Near Edge Structure in $\mathrm{KBr}$ and $\mathrm{RbCl}$," I.E. Stekhin, A.V.Soldatov and R. Ingalls, 8th International Conference on X-Ray Absorption Fine Structure, Berlin, Aug. 28 - Sept. 2, 1994.

"EXAFS Study of Pressure Induced Amorphization," F. Wang and R. Ingalls, American Physical Society Conference, San Jose, California, March 1994.

"XAFS Study of Pressure Induced Amorphization," F. Wang and R. Ingalls, AIRAPT International High Pressure Conference, Warsaw, Sept. 11-15, 1995.

"XAFS Study of the B1-B2 Transition in RbCl," R. Ingalls, S. Jones and F. Wang, AIRAPT International High Pressure Conference, Warsaw, Sept. 11-15, 1995.

"The Effect of Hydrostatic Pressure on the Local Structure of $\mathrm{K}_{1-x} \mathrm{Na}_{x} \mathrm{TaO}_{3}$ and $\mathrm{KTa}_{1-x} \mathrm{Nb}_{x} \mathrm{O}_{3}, "$ F. Wang, B. Ravel, Y. Yacoby, E.A. Stern and R. Ingalls, Ninth International Conference on X-Ray Absorption Fine Structure, Grenoble, Aug. 26-30, 1996.

"Phase Transitions under Extremely High Pressure," I.E. Stekhin, A.V. Soldatov and R. Ingalls, Ninth International Conference on X-Ray Absorption Fine Structure, Grenoble, Aug. 26-30, 1996. 


\section{PhD Theses}

"EXAFS Experiments at High Pressure with Small Samples" John Whitmore University of Washington, September, 1994

"High Pressure Studies of Iron Hydroxide, Iron Silicate Spinel and Sodium Nitroprusside" In-Jerng Choe University of Washington, December, 1994

\section{Personnel}

Robert Ingalls - Principal Investigator

John Whitmore - Graduate Student

In-Jerng Choe - Graduate Student

Fuming Wang - Graduate Student

Shelley Kelly- Graduate Student

B. Houser - Collaborator (Eastern Washington University)

E.A. Stern and J.J. Rehr - Collaborators (University of Washington)

A. V. Soldatov - Collaborator (Rostov University)

Y. Yacoby - Collaborator (Racah Institute)

A. Voronel - Collaborator (Tel Aviv University) 